\title{
Psychiatrists are experts when it comes to missing boats. Will prevention be the next one?
}

\author{
Celso Arango ${ }^{1}$ \\ Published online: 5 November 2019 \\ ○) Springer-Verlag GmbH Germany, part of Springer Nature 2019
}

\begin{abstract}
"Kingdoms that are governed with remedies rather than prevention are headed for disaster"-Don Juan de Palafox y Mendoza (1600-1659).

One of the recent major changes in the paradigm of conceptualizing mental disorders has been a shift from silos of risk factors for specific DSM/ICD disorders to a paradigm of multiple common risk factors (including genetic, environmental, and epigenetic) that interact in a pluripotential brain and that may end up causing symptoms of different severities for a given mental disorder or not causing any disorder (with the potential influence of protective factors). Multiple studies have shown common genetic (Cross Disorder Group of the Genomics Psychiatric Consortium, Brainstorm Consortium et al.) [1,2] and environmental risk factors such as bullying or child abuse [3] for most mental disorders. This new approach better captures the complexity of mental disorders and the many different stages between the genes and the behaviour.
\end{abstract}

Three papers in this issue adopt this paradigm from different angles. In this issue, Kircher et al. [4] describe the ambitious objectives of a large consortium (FOR2107) in order to unravel schizophrenia. The neurobiological correlates whereby genetic and environmental factors exert their influence on brain structure, function, and course of illness in different psychoses such as major depression, bipolar disorder, schizoaffective disorder, and schizophrenia will be studied in different large cohorts.

In this issue, Zhang et al. [5] assess the relationship between outcomes (symptomatic and functional recovery) and duration of untreated prodromal symptoms in a large cohort of individuals with attenuated psychosis syndrome

Celso Arango

carango@hggm.es

1 Child and Adolescent Psychiatry Department, Institute of Psychiatry and Mental Health, Hospital General Universitario Gregorio Marañón, School of Medicine, Universidad Complutense, IiSGM, CIBERSAM, Madrid, Spain
(APS) followed for up to 2 years. Longer duration of untreated prodromal symptoms of psychosis was associated with poor functional outcome regardless of diagnosis after a first psychotic episode.

In a similar approach, Kleineidam et al. [6] assess saccadic eye movements in subjects in an at-risk mental state (ARMS). Those who were in a late at-risk mental state, as defined by attenuated psychotic symptoms or brief limited intermittent psychotic symptoms had, as was the case with first-episode patients, increased antisaccade latencies compared with controls. However, no saccadic measure predicted conversion to psychosis within 2 years. The authors suggest that this neurophysiological marker may be sensitive to disease severity along the continuum of psychosis, as it was present not only in first-episode patients with schizophrenia and those with more severe symptoms (some of whom will develop psychotic disorders other than schizophrenia), but also in those in early at-risk mental state.

The new paradigm of pluripotentiality in the brain depending on the infinite combination of genetic and environmental factors and their interactions and temporal dimension (an interaction of a specific allele or CNV with environmental risk factors is not the same at different times: in utero or at birth, in adolescence, etc.) has profound implications for prevention in psychiatry. For too long we have focused on tertiary prevention when it is clear that secondary and primary prevention (and even health promotion) are much more cost-effective [7]. Our colleagues in other areas of medicine (e.g. cardiology, oncology, infectious diseases, etc.) noticed this long ago, and contrary to us, have acted upon it. It is very difficult to find a really high-impact journal that does not include trials on primary prevention of cardiovascular diseases, oncological diseases, and so forth. A report from a UK mental health research charity, MQ, sadly shows that less than $4 \%$ of all metal health research is devoted to prevention. This is despite the fact that really should make all the difference, which is that many of these preventative interventions save money and some of them, 
such as early intervention in psychosis, have a total return on investment of almost $18 \mathrm{lb}$ for each pound investedor the even more striking savings of $83 \mathrm{lb}$ for each pound invested in prevention of conduct disorders through social and emotional learning programmes [8]. It is no surprise that the ROAMER project, which addressed the mental health research priorities for Europe, identified research into mental health prevention, mental health promotion, and interventions in children, adolescents, and young people as the number one priority [9]. Despite these striking facts, most governments are still looking elsewhere [10].

Knowledge of the risk factors for mental disorders is the first step toward preventive interventions. Knowledge of the link between those risk factors and the advent of psychopathological symptoms and constellations of those symptoms forming mental disorders will not only help to avoid the risk factors, but will accelerate treatment-targeted research.

A priority for the immediate future of psychiatry should be to focus on early (and very early) interventions that cut across different disorders. Eventually, specific interventions in developmentally sensitive periods may reduce the incidence of mental disorders or shift the evolution towards less severe presentations. All these interventions must be illuminated by basic and translational research explaining the links between the intervention and the potential benefit.

\section{References}

1. Cross-Disorder Group of the Psychiatric Genomics Consortium (2013) Identification of risk loci with shared effects on five major psychiatric disorders: a genome-wide analysis. Lancet 381:1371-1379

2. Brainstorm Consortium et al (2018) Analysis of shared heritability in common disorders of the brain. Science 360(6395):eaap8757

3. Teicher MH, Samson JA (2013) Childhood maltreatment and psychopathology: a case for ecophenotypic variants as clinically and neurobiologically distinct subtypes. Am J Psychiatry 170:1114-1133

4. Kircher T, Wöhr W, Nenadic I, Schwarting R, Schratt G, Alferink J, Culmsee C, Garn H, Hahn T, Müller-Myhsok B, Dempfle A, Hahmann M, Jansen A, Pfefferle P, Renz H, Rietschel M, Witt SH, Nöthen M, Krug A, Dannlowski U (2018) Neurobiology of the major psychoses: a translational perspective on brain structure and function-the FOR2107 consortium. Eur Arch Psychiatry Clin Neurosci. https://doi.org/10.1007/s00406-018-0943-X

5. Zhang T, Xu L, Tang Y, Cui H, Tang X, Wei Y, Wang Y, Hu Q, Qian Z, Liu X, Li C, Wang J (2018) Relationship between duration of untreated prodromal symptoms and symptomatic and functional recovery. Eur Arch Psychiatry Clin Neurosci. https:// doi.org/10.1007/s00406-018-0917-z

6. Kleineidam L, Frommann I, Ruhrmann S, Klosterkötter J, Brockhaus-Dumke A, Wölwer W, Gaebel W, Maier W, Wagner M, Ettinger U (2019) Antisaccade and prosaccade eye movements in individuals clinically at risk for psychosis: comparison with first-episode schizophrenia and prediction of conversion. Eur Arch Psychiatry Clin Neurosci. https://doi.org/10.1007/s0040 6-018-0973-4

7. Arango C, Díaz-Caneja CM, McGorry PD, Rapoport J, Sommer IE, Vorstman JA, McDaid D, Marín O, Serrano-Drozdowskyj E, Freedman R, Carpenter W (2018) Preventive strategies for mental health. Lancet Psychiatry 5(7):591-604

8. Knapp M, McDaid D, Parsonage M (2011) Mental health promotion and mental illness prevention: the economic case. Department of Health, London. http://eprints.1se.ac.uk/32311/

9. Wykes T, Haro JM, Belli SR, Obradors-Tarragó C, Arango C, Ayuso-Mateos JL, Bitter I, Brunn M, Chevreul K, DemotesMainard J, Elfeddali I, Evans-Lacko S, Fiorillo A, Forsman AK, Hazo JB, Kuepper R, Knappe S, Leboyer M, Lewis SW, Linszen D, Luciano M, Maj M, McDaid D, Miret M, Papp S, Park AL, Schumann G, Thornicroft G, van der Feltz-Cornelis CM, van Os J, Wahlbeck K, Walker-Tilley T, Wittchen HU, ROAMER Consortium (2015) Mental health research priorities for Europe. Lancet Psychiatry 2:1036-1042

10. Arango C, Bernardo M, Bonet P, Cabrera A, Crespo-Facorro B, Cuesta MJ, González N, Parrabera S, Sanjuan J, Serrano A, Vieta E, Lennox BR, Melau M (2017) When the healthcare does not follow the evidence: the case of the lack of early intervention programs for psychosis in Spain. Rev Psiquiatr Salud Ment 10:78-86 